Article

\title{
Effect of Microwave Cure on the Thermo-Mechanical Properties of Tung Oil-Based/Carbon Nanotube Composites
}

\author{
Madeline Smith, Amanda Payne, Kyle Edwards, Steven Morris, Brenda Beckler and \\ Rafael L. Quirino* \\ Chemistry Department, Georgia Southern University, Statesboro, GA 3046, USA; \\ E-Mails: ms06963@georgiasouthern.edu (M.S.); am02837@georgiasouthern.edu (A.P.); \\ ke01197@georgiasouthern.edu (K.E.); sm03789@georgiasouthern.edu (S.M.); \\ bb04890@georgiasouthern.edu (B.B.) \\ * Author to whom correspondence should be addressed; E-Mail: rquirino@georgiasouthern.edu. \\ Academic Editor: Alessandro Lavacchi
}

Received: 30 July 2015 / Accepted: 14 September 2015 / Published: 17 September 2015

\begin{abstract}
Tung oil is uniquely reactive among plant-based natural oils due to the series of conjugated carbon-carbon double bonds in its fatty acid chains. These conjugated carbon-carbon double bonds impart a high reactivity towards cationic polymerization in the presence of other reactive co-monomers, such as divinylbenzene and styrene. An impressive decrease in the cure time of tung oil-based thermosets has been achieved when the resins investigated were microwaved in the presence of carbon nanotubes (CNTs). However, the fast cure compromised the overall thermo-mechanical properties of the materials investigated. Microwave power, exposure time, and CNT loading effects have been assessed by means of dielectric analysis (DEA), thermogravimetric analysis (TGA), differential scanning calorimetry (DSC), dynamic mechanical analysis (DMA), and proton nuclear magnetic resonance $\left({ }^{1} \mathrm{H}\right.$ NMR) spectroscopy of extracts obtained by Soxhlet extraction. Possible reasons were proposed to explain the overall inferior properties observed whenever faster cure rates were achieved.
\end{abstract}

Keywords: bio-based materials; microwaves; carbon nanotubes; tung oil; cationic polymerization 


\section{Introduction}

The partial replacement of petroleum-derived plastics and composites by bio-based materials from inexpensive, renewable, and natural resources has the potential to greatly impact the plastics and composites industries. Natural starting materials, such as vegetable oils, are readily available in large quantities, low cost, and have the potential to offer properties not currently available in commercial petroleum-based products. These promising characteristics, and the increasing attention bio-renewable chemicals have been receiving in both industrial, and academic settings is expected to lead to significant progress towards environmental sustainability in the near future [1,2].

In recent years, a variety of vegetable oil-based polymers with tunable thermal and mechanical properties have been developed by the free radical, or cationic co-polymerization of regular and modified vegetable oils in the presence of divinylbenzene (DVB), styrene (ST), and/or maleic anhydride [3,4]. In such systems, the reactive sites in the triglyceride units are the carbon-carbon double bonds along the fatty acid chains. Overall, the reactivity of vegetable oils towards these polymerization processes is significantly higher when the carbon-carbon double bonds are conjugated [5]. Furthermore, the higher the degree of unsaturation of an oil, the higher the crosslink density of its resulting co-polymer, and the better its mechanical properties [3].

Over the years, due to an increasing demand for bio-based monomers and drying oils, a number of processes for the conjugation of carbon-carbon double bonds in regular vegetable oils have been developed with the goal of enhancing their reactivity towards polymerization and auto-oxidation [6-10]. With a high percentage of fatty acids $(\sim 84 \%)$ [11] bearing a natural system of triply conjugated carbon-carbon double bonds (Figure 1), tung oil constitutes an ideal candidate for the preparation of bio-based materials. Indeed, the carbon-carbon double bonds in tung oil can readily react with vinyl co-monomers, such as DVB, ST, and dicyclopentadiene, via cationic, thermal, or free radical polymerizations, without the need for structural modifications. It has been shown that these reactions result in highly crosslinked polymer networks [12-15]. Likewise, tung oil has been used as a key component in cationic bio-based thermosets by crosslinking it with limonene and myrcene [16].

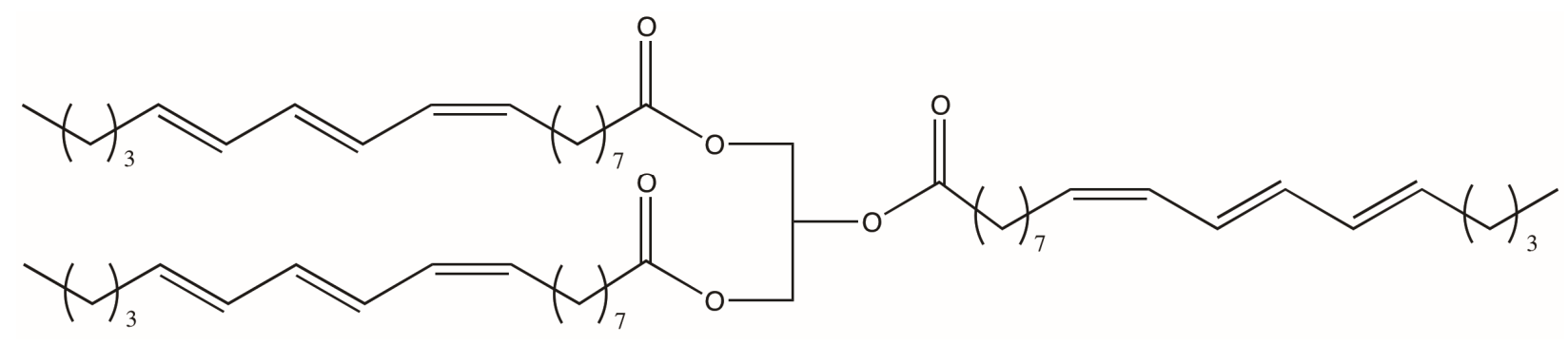

Figure 1. Chemical structure of tung oil.

Tung oil has also been used in more straight-forward applications, such as protecting coatings for wood surfaces [17], and protein films [18], or as a strengthening additive for unsaturated polyester resins [19]. More complex systems have been obtained by the Diels-Alder reaction of carbon-carbon double bonds in tung oil with dienophiles [20]. These Diels-Alder adducts have been used as diluents in soybean oil-based alkyd resins [20]. Similarly, tung oil fatty acid derivatives have been simultaneously crosslinked with the ring-opening of anhydrides, and the Diels-Alder reaction with dienophiles [21]. 
Most of these, and other related systems, are obtained through conventional heating, ultra-violet irradiation (UV), or $\gamma$ irradiation techniques. Recently, the alternative Infra-red curing of tung oil films has been investigated [22]. In unrelated applications, tung oil has been employed as a promising starting material for the preparation of biodiesel [23]. When tung oil is used to produce biodiesel, a high percentage of monoglycerides are formed in comparison to either a soybean oil/tung oil mixture or pure sunflower oil [23].

The properties of composites prepared from the reinforcement of regular petroleum-based thermoplastics, such as polystyrene [24], polyethylene terephthalate [25], polymethyl methacrylate [26], and polypropylene [27], with single and multiwalled carbon nanotubes (CNTs) have been extensively investigated to date. The study of CNT composites with bio-based resins has, so far, focused heavily on the use of polylactic acid as the matrix [28], finding application mainly in the biomedical field [29]. Nevertheless, vegetable oil-based thermosetting resins have been reinforced with continuous glass fibers and cationically cured at $110{ }^{\circ} \mathrm{C}[30]$, which suggests that cationic tung oil resins may be cured in a similar fashion in the presence of CNTs.

Microwave reactions have been used to speed-up and simplify reactions by removing the need for a solvent [31]. For example, amides have been synthesized with the Aza-Wittig reaction under microwaves in the absence of a solvent [31]. The conducting behavior of CNTs can be utilized for the fabrication of electrochemical sensors [32]. Indeed, multiwalled CNTs modified with tin oxide, have been used to detect levofloxacin [32]. The microwave absorbing properties of metallic and aligned multi-walled carbon nanotubes (MWCNTs) have been proposed as a purification procedure during the preparation of semi-conductive CNTs, as well as for a new illumination technology [33]. More recently, the deposition of various metal nanoparticles on MWCNTs has been achieved after the instantaneous decomposition of transition metal acetates under microwaves [34]. It has also been shown that the efficient carbothermal reduction of copper oxide $(\mathrm{CuO})$ can be achieved by microwave heating in the presence of MWCNTs [35]. The key to CNT-assisted microwave reactions lies in carbon's ability to intensely absorb microwaves, which leads to rapid heating. These properties of CNTs have been used in the curing of epoxy resins to yield CNT composites with better dielectric properties than composites prepared with conventional heating [36,37]. Despite the aforementioned interesting examples, reports on the effect of microwave heating of CNTs on the cure and thermo-mechanical properties of polymeric resins are scarce.

After preliminary trials, it was quickly noticed that the properties of tung oil-based CNT composites cured under microwaves differed greatly from those of similar composites, with the same composition, cured in a regular convection oven. In addition to a significantly reduced cure time, the former presented obvious lower overall mechanical properties than the latter. The current work provides a careful investigation of the effects of a fast microwave cure on the thermo-mechanical properties of tung oil-based CNT composites.

In the presence of CNTs, the heating effect of microwaves is magnified. This phenomenon is used here in order to significantly reduce the cure time of tung oil-based thermosets. A thorough evaluation of the CNT-assisted microwave cure of cationic co-polymers has been carried out. A brief study of the cure-kinetics of the cationic co-polymerization of tung oil, DVB, and ST under microwaves, with and without CNTs, is presented on the basis of differential scanning calorimetry (DSC), and Soxhlet extraction results. The influence of CNT loading on reaction time and completeness is shown. Strong 
emphasis is given to the impact of microwave cure on the mechanical properties of the final materials by a comparison of Dynamic Mechanical Analysis (DMA) results of samples cured under microwaves and conventional heating.

This work shows that cure times can be significantly reduced at the expense of mechanical properties when microwaves are used as the heating source in the presence of CNTs. The findings reported in this manuscript are relevant for furthering the understanding of the fundamentals of microwave effects in the cure-kinetics of thermosets in the presence of CNTs. The goal of this manuscript is to demonstrate that the combination of microwaves and CNTs for the fast cure of thermosetting composites is indeed detrimental to the mechanical properties of the system, despite the great reduction in cure time.

\section{Experimental}

\subsection{Materials}

DVB was purchased from TCI America (Portland, OR, USA), ST was purchased from Acros Organics (New Jersey, NJ, USA), and Boron tri-fluoride etherate $\left(\mathrm{BF}_{3} \cdot \mathrm{OEt}_{2}\right)$ was purchased from (Alfa Aesar, Ward Hill, MA, USA). Dimethyl sulfoxide (DMSO) and dichloromethane were purchased from Fisher Scientific (Pittsburgh, PA, USA). Tung oil (iodine index $>220$, and acid number $<6.9 \mathrm{mg}$ $\mathrm{KOH} / \mathrm{g}$ of oil) was purchased from Sigma-Aldrich (St. Louis, MO, USA). Soybean Oil was purchased from a local grocery store (Great Value brand), and multi-walled carbon nanotubes (MWCNTs), with a nominal diameter of 20-50 nm, were purchased from Cheaptubes (Grafton, VT, USA). All chemicals and materials were used as received, without any further modification.

\subsection{Methods}

\subsubsection{Settling Tests}

An amount of $50.0 \mathrm{mg}$ of CNTs was added to $2 \mathrm{~mL}$ of the solvent in a glass vial and the mixture was sonicated in a sonication bath for $5 \mathrm{~min}$. The samples were then left on a flat surface and photos were taken at pre-determined time intervals to show the progressive precipitation of CNTs in different solvents.

\subsubsection{Heating Rates}

In a test tube, pre-determined amounts of CNTs were sonicated in $10 \mathrm{~mL}$ of tung oil for $5 \mathrm{~min}$. The heating rates of CNTs suspended in tung oil were determined by immersing the microwave temperature probe in the mixture, and microwaving the system at pre-set powers until a temperature of $90{ }^{\circ} \mathrm{C}$ was attained. The temperature change, and the time required to reach $90{ }^{\circ} \mathrm{C}$ were used to calculate the heating rates. The experiment was conducted in triplicate for each combination of CNT concentration and microwave power, and the standard deviation of the measurements is reported.

\subsubsection{Sample Preparation Using a Convection Oven}

DVB (15 wt \%), ST (10 wt \%), and tung oil (70 wt \%) were initially thoroughly mixed in a glass vial with the aid of a Vortex ( $\sim 1 \mathrm{~min})$. Whenever used, pre-determined amounts of CNTs were added to the reaction mixture, and sonicated in a sonication bath for $5 \mathrm{~min}$. A small layer of soybean oil (3 wt \%) was 
then applied on top of the reaction mixture, before addition of $\mathrm{BF}_{3} \cdot \mathrm{OEt}_{2}(2 \mathrm{wt} \%)$, in order to prevent the Lewis acid from reacting too quickly with the monomers at room temperature. After the addition of $\mathrm{BF}_{3} \cdot \mathrm{OEt}_{2}$, the reaction mixture was once again vortexed in order to ensure the homogeneity of the system, and the capped vial was allowed to rest for $30 \mathrm{~min}$ at room temperature, which ensured gellation with minimum CNT precipitation and favored a better CNT distribution throughout the matrix. The sample was then heated directly in a regular convection oven, under the conditions described in the discussion. Figure S1 provides a scheme of the sample preparation.

\subsubsection{Sample Preparation Using a Microwave Reactor}

All microwave experiments were performed in an Ethos microwave reactor (Milestone, Shelton, CT, USA), with an output frequency of $2450 \mathrm{MHz}$, and adjustable power from 0 to $2500 \mathrm{~W}$. The microwave samples were prepared using the same procedure employed for the preparation of samples cured in the convection oven. The glass vials were capped with a rubber cap to avoid competing microwave absorption with the monomers and CNTs. The capped vials were placed directly in a Teflon jacket and submitted to appropriate microwave conditions. Multiple preliminary experiments under various powers and times led to the optimum schedule of $10 \mathrm{~min}$ at $100 \mathrm{~W}$, followed by $10 \mathrm{~min}$ at $200 \mathrm{~W}$. Samples that required a post-cure step after microwave curing were quickly transferred from the microwave reactor into a pre-heated oven at a pre-set temperature. Further details of the microwave reactions are discussed later in the text.

\subsection{Characterization}

In order to determine the optimum curing time, dielectric analysis (DEA) experiments were conducted with an Epsilon DEA 230/1 cure monitor (Netzsch Instruments North America LLC, Burlington, MA, USA) equipped with a flexible probe that was immersed in the resin during curing. After the cationic process initiated at room temperature while the sample rested for $30 \mathrm{~min}$, the cure was completed in a convection oven kept at $140^{\circ} \mathrm{C}$. That temperature was chosen based on the cure of related systems [11,30], and preliminary tests with the resin composition reported here. As a matter of fact, it has been previously shown that soybean oil-based cationic composites reinforced with continuous glass fibers were successfully cured over the course of $10 \mathrm{~h}$ at $110^{\circ} \mathrm{C}$ after a $30 \mathrm{~min}$ pre-heating time [30]. A slightly higher temperature was chosen with the goal of reducing cure time and due to differences in the resin composition in comparison to previously studied systems [30]. The DEA tests were run for $12 \mathrm{~h}$ with frequencies ranging from 0.3 to $10,000.0 \mathrm{~Hz}$. The permittivity and loss factor of the samples were measured as a function of time. The results presented in the text correspond to a plot of ion viscosity $(\Omega$ $\mathrm{cm}) v s$. time for a $\sim 10 \mathrm{~g}$ sample.

Differential Scanning Calorimetry (DSC) experiments were conducted with a Q20 DSC instrument (TA Instruments, New Castle, DE, USA). Samples of $\sim 10 \mathrm{mg}$ were heated, under a $\mathrm{N}_{2}$ atmosphere, from -30 to $200{ }^{\circ} \mathrm{C}$ at a heating rate of $10{ }^{\circ} \mathrm{C} \mathrm{min}^{-1}$. Thermogravimetry (TG) experiments were performed on a Q50 thermobalance (TA Instruments, New Castle, DE, USA) with samples of approximately $10 \mathrm{mg}$, under an air atmosphere, from room temperature to $650{ }^{\circ} \mathrm{C}$, at a heating rate of $20^{\circ} \mathrm{C} \mathrm{min}^{-1}$.

A Q800 DMA (TA Instruments, New Castle, DE, USA), with a tension fixture, was used for all dynamic mechanical analysis (DMA) experiments. Samples were cut into $23.0 \mathrm{~mm} \times 10.0 \mathrm{~mm} \times$ 
$2.2 \mathrm{~mm}$ (length $\times$ width $\times$ thickness, respectively) specimens. The specimens were heated from -60 to $150{ }^{\circ} \mathrm{C}$, at a heating rate of $3{ }^{\circ} \mathrm{C} \mathrm{min}^{-1}$, in iso-strain mode, with a frequency of $1 \mathrm{~Hz}$, and amplitude of $14 \mu \mathrm{m}$. The experiments were repeated to ensure consistency, and the results presented here reflect the average of two measurements that only differ by a maximum of $10 \%$. The $T_{\mathrm{g}}$ values reported in this manuscript were determined based on the peak maxima of the tan $\delta$ curve of each sample.

Composite samples of 1-3 g underwent Soxhlet extraction for $24 \mathrm{~h}$ with dichloromethane. The solvent was removed from the extracts using a rotary evaporator. Soluble and insoluble materials were dried in a vacuum oven at $70{ }^{\circ} \mathrm{C}$ overnight. After weighing the recovered materials, the soluble portions were dissolved in deuterated chloroform for proton nuclear magnetic resonance $\left({ }^{1} \mathrm{H}\right.$ NMR) spectroscopy analysis. The ${ }^{1} \mathrm{H}$ NMR spectra were obtained on an Agilent MR400DD2 spectrometer (Santa Clara, CA, USA) operating at $400 \mathrm{MHz}$.

\section{Results and Discussion}

\subsection{Resin Composition}

It has been previously shown that the thermal, and the cationic polymerizations of mixtures of ST, DVB, and tung oil, at various ratios, can be successfully accomplished [11,38]. Furthermore, other similar resins containing $45 \mathrm{wt} \%$ of a variety of conjugated vegetable oils have been consistently prepared, and yielded materials with interesting thermo-mechanical properties [4]. It has also been shown that when vegetable oils are cationically co-polymerized with mixtures of DVB and ST, a homogeneous material is obtained [4]. In a related work, evaluating the concentration of DVB in conjugated vegetable oil-based resins cured by free radical polymerization, it has been shown that samples containing $15 \mathrm{wt} \%$ of DVB exhibit good mechanical properties [5]. In the current work, preliminary tests with a range of concentrations of tung oil and ST, showed that the resins containing $70 \mathrm{wt} \%$ of tung oil, $15 \mathrm{wt} \%$ of DVB, $10 \mathrm{wt} \%$ of ST, $3 \mathrm{wt} \%$ of soybean oil, and $2 \mathrm{wt} \% \mathrm{of} \mathrm{BF}_{3} \cdot \mathrm{OEt}_{2}$ exhibit a gellation time of $30 \mathrm{~min}$ at room temperature. When the amount of tung oil employed was higher than $70 \mathrm{wt} \%$, the final material wasn't strong enough to be handled without easily breaking, and the gellation times were significantly longer. When the amount of ST was higher than $10 \mathrm{wt} \%$, the reaction was too violent and too fast, and a safe procedure could not be envisioned for the system.

\subsection{Cure in a Convection Oven}

Once the co-monomer composition was set for the resin system under study, a DEA experiment was conducted in order to determine the optimal cure time for the resin. Figure 2 shows the curve of $\log$ ion viscosity $v s$. time for the cure carried out in a convection oven at $140{ }^{\circ} \mathrm{C}$. As mentioned previously in the text, this temperature was chosen based on previously published data of related resins [11,30], and preliminary tests. According to the sample preparation method employed in this work, it is expected that polymer chain growth starts immediately after mixing the resin components with $\mathrm{BF}_{3} \cdot \mathrm{OEt}_{2}$, following a cationic polymerization mechanism that predominates during the initial $30 \mathrm{~min}$ resting time that precedes heating. Because no effort has been made to suppress oxygen from the capped vials used, an auto-oxidation process triggered by the presence of oxygen at high temperatures cannot be excluded under the conditions employed [39], especially during longer reaction times. As the temperature is 
increased to $140{ }^{\circ} \mathrm{C}$, it is possible that both cationic and free radical reactions coexist in the system, contributing to the final cure of the thermoset. Indeed, the thermal polymerization of similar tung oilbased resins in the absence of cationic or free radical initiators has been demonstrated and addressed previously in the literature [11].

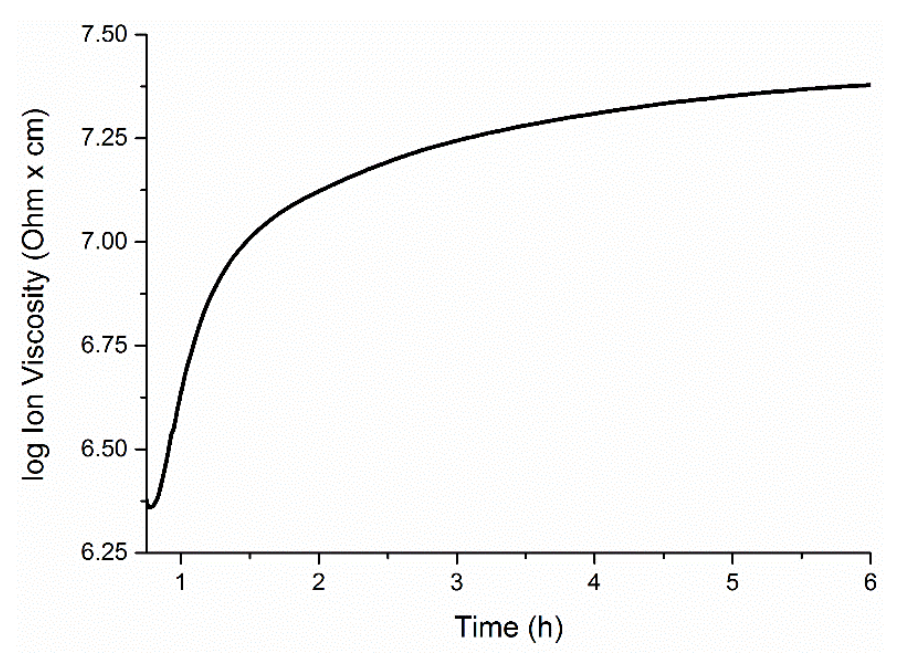

Figure 2. Dielectric analysis (DEA) of the cure of a tung oil-based thermosetting resin at $140{ }^{\circ} \mathrm{C}$. The resin is composed of $70 \mathrm{wt} \%$ of tung oil, $15 \mathrm{wt} \%$ of divinylbenzene (DVB), $10 \mathrm{wt} \%$ of styrene (ST), $3 \mathrm{wt} \%$ of soybean oil, and $2 \mathrm{wt} \%$ of $\mathrm{BF}_{3} \cdot \mathrm{OEt}_{2}$.

After initial heating (first $45 \mathrm{~min}$. not shown), the growth of polymer chains predominates in the system, and a steady increase in the ion viscosity, due to the lower mobility of the resin components, is noticed during the following $30 \mathrm{~min}$ (Figure 2). After $1 \mathrm{~h}$ and $15 \mathrm{~min}$, the increase in ion viscosity slows down gradually until the resin is fully cured and the ion viscosity plateaus. The complete polymerization of the resin is attained after $8 \mathrm{~h}$. However, the change in ion viscosity between 6 and $8 \mathrm{~h}$ is negligible for practical purposes, and, as will be shown next with the DSC results, further cure of the system can't be detected after $6 \mathrm{~h}$.

In order to confirm the ideal cure time, sample mixtures were prepared and heated at $140{ }^{\circ} \mathrm{C}$ in a convection oven, for different times. Each one of these samples was analyzed by DSC in order to check for residual cure of the polymer. Indeed, the eventual residual cure of a sample leads to an exotherm at approximately $230{ }^{\circ} \mathrm{C}$. Figure 3 presents the DSC curves of samples cured for $1.5 \mathrm{~h}, 3.5 \mathrm{~h}, 5.5 \mathrm{~h}$, and $6 \mathrm{~h}$. From the curve of the sample cured for $1.5 \mathrm{~h}$, an obvious exothermic peak is seen at approximately $230{ }^{\circ} \mathrm{C}$ (Figure 3). The area under that peak clearly decreases with increases in cure time. Indeed, a clearly lower area is observed, at the same temperature, for the sample cured for $3.5 \mathrm{~h}$. The trend is maintained with the sample cured for $5.5 \mathrm{~h}$, but when the resin is heated for $6 \mathrm{~h}$, no exothermic peaks could be detected by the DSC. Therefore, the DSC data confirms the results obtained from the DEA, and $6 \mathrm{~h}$ was selected as the ideal heating time for the preparation of the tung oil thermosetting resins reported here. The more discrete transitions occurring at other temperatures will be discussed later in the text, when analyzing the DMA data. A quick analysis of Figure 3 suggests that the cure behavior matches a self-catalyzed process. Further kinetic experiments are necessary in order to fully elucidate the cure mechanism. 


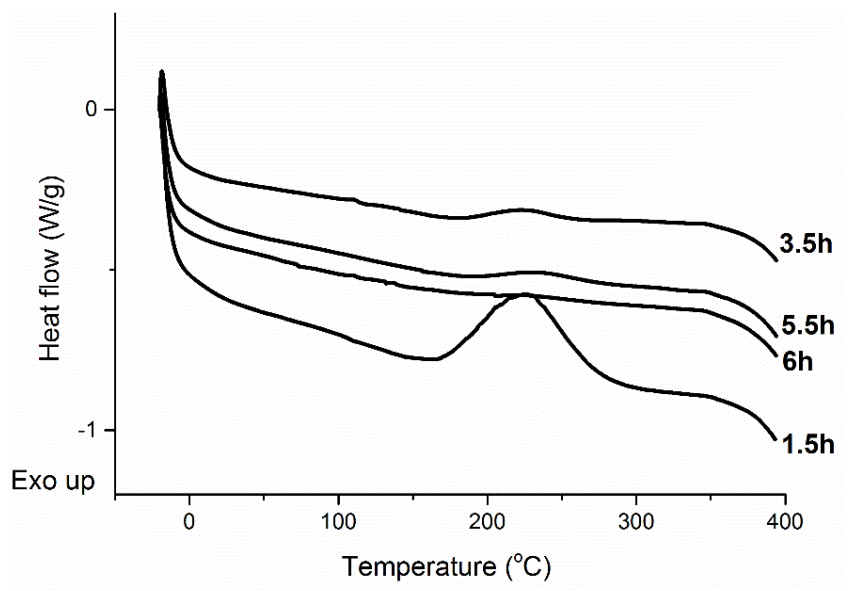

Figure 3. Differential scanning calorimetry (DSC) curves of tung oil-based thermosetting resins cured for $1.5 \mathrm{~h}, 3.5 \mathrm{~h}, 5.5 \mathrm{~h}$, and $6 \mathrm{~h}$ at $140{ }^{\circ} \mathrm{C}$. The resin is composed of $70 \mathrm{wt} \%$ of tung oil, $15 \mathrm{wt} \%$ of DVB, $10 \mathrm{wt} \%$ of ST, $3 \mathrm{wt} \%$ of soybean oil, and $2 \mathrm{wt} \%$ of $\mathrm{BF}_{3} \cdot \mathrm{OEt}_{2}$.

\subsection{Microwave Cure in the Presence of CNTs}

One of the most common limitations for the preparation of good CNT composites is the tendency for agglomeration and precipitation of this carbon species in a variety of solvents. It can be seen in Figure 4, however, that a negligible precipitation of CNTs is observed after $60 \mathrm{~min}$ of its suspension in tung oil and in the crude resin (Figure 4). When DMSO is used as the solvent, CNTs start precipitating almost instantly after suspension, and the majority of CNTs have completely precipitated after 60 min (Figure 4). Besides the higher viscosity of tung oil in comparison to DMSO, which helps to keep the CNTs suspended, it is believed that the polarity of the solvent greatly affects its interaction with the CNTs. In the case of triglycerides, the long chain fatty acids confer a strong non-polar character to the molecule, which favors van der Waals interactions with CNTs, helping to achieve a good dispersion for at least 60 min in the crude resin. In this project, achieving a good dispersion of CNTs in vegetable oil is crucial for maximizing the heat transfer from CNTs to the resin under microwaves. As indicated in Figure 4 and as suggested by the examination of composites after the cure (Figure 5-discussed later in the text), the CNT suspensions generated in this work are stable enough for sufficient time to allow for consolidation of the thermoset, potentially resulting in a composite with well-dispersed CNTs. When the initiator for the cationic polymerization is added to the crude mixture of co-monomers and CNTs, gellation happens within $30 \mathrm{~min}$, potentially maintaining the original suspension of CNTs. During the subsequent cure stages, the polymer is consolidated and a final material, which most likely contains evenly dispersed CNTs, is obtained. Indications of a good CNT dispersion in the final composites can be seen in Figure 5.

The extraordinary heat generated by the microwave irradiation of CNTs is the result of localized Joule heating from the interaction of RF electromagnetic waves and the nanostructured carbon material. Table 1 shows the heating rates obtained for suspensions of CNTs in tung oil irradiated under different microwave powers. As expected, an increase in microwave power results in an increase of the heating rates, regardless of the CNT concentration (Table 1). Moreover, for microwave powers between 100 and $500 \mathrm{~W}$, increasing the CNT concentration results in an increase of the heating rates. It is interesting to notice, however, that a greater increase in the heating rate with CNT concentration, in proportional terms, is observed at lower powers. For instance, when irradiated at $100 \mathrm{~W}$, the measured heating rate of a 
suspension with $0.25 \mathrm{wt} \%$ of CNT is approximately 1.8 times higher than that of pure tung oil (Table 1). At $500 \mathrm{~W}$, the heating rate of a suspension with $0.25 \mathrm{wt} \%$ of CNTs is only approximately 1.3 times higher than that of pure tung oil (Table 1). The heating rates discussed here were determined in a short time interval in comparison to the cure of the tung oil resins discussed next. It is possible, therefore, that over the course of the extended cure times under microwaves, the average heating rates may differ from the ones reported in Table 1. However, the results in Table 1 are still representative of the effect of adding CNTs to triglyceride-based resins cured under microwaves.

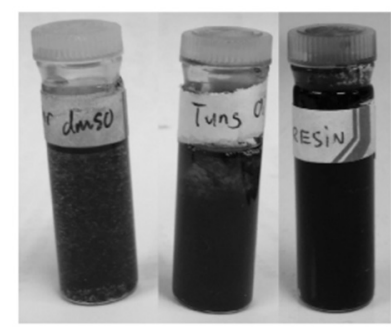

(a) (b) (c)

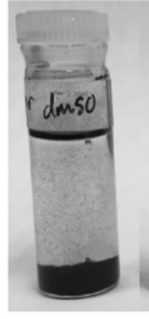

(d)

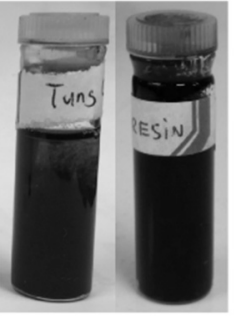

(e) (f)

Figure 4. Settling tests comparing suspensions of carbon nanotubes (CNTs) in tung oil, dimethyl sulfoxide (DMSO), and the crude monomer mixture comprised of $1.4 \mathrm{~g}$ of tung oil, $0.2 \mathrm{~g}$ of divinylbenzene, and $0.3 \mathrm{~g}$ of styrene. (a) CNTs in DMSO after resting for $5 \mathrm{~min}$; (b) CNTs in tung oil after resting for $5 \mathrm{~min}$; (c) CNTs in the crude monomer mixture after resting for $5 \mathrm{~min}$; (d) CNTs in DMSO after resting for $60 \mathrm{~min}$; (e) CNTs in tung oil after resting for $60 \mathrm{~min}$; and (f) CNTs in the crude monomer mixture after resting for $60 \mathrm{~min}$.
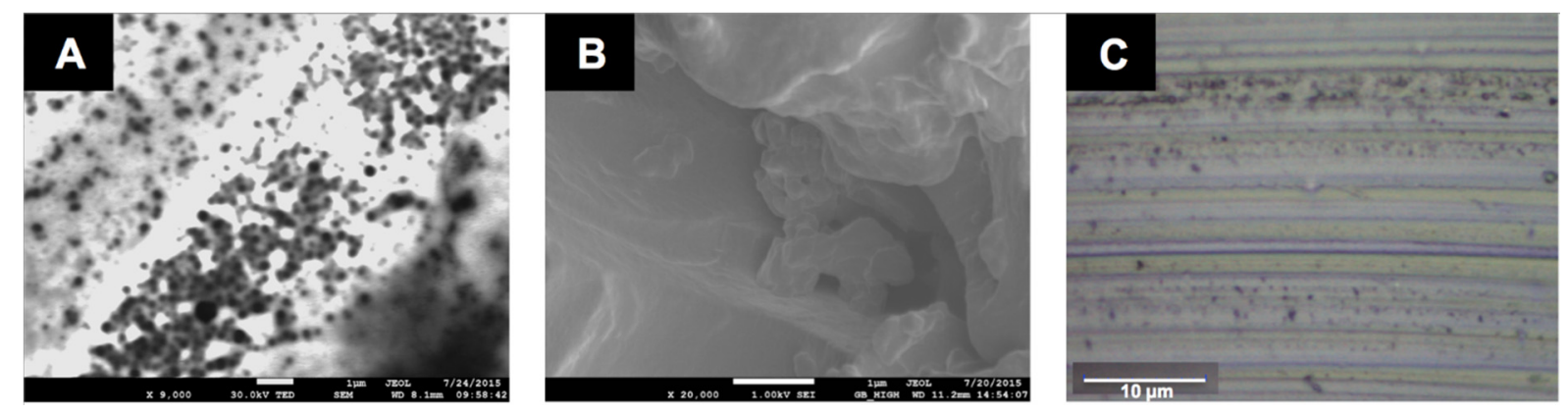

Figure 5. Tung oil-based resin bearing $0.25 \mathrm{wt} \%$ of CNTs and cured under microwaves at $100 \mathrm{~W}$ for $10 \mathrm{~min}$, followed by $200 \mathrm{~W}$ for $10 \mathrm{~min}$, and a $1 \mathrm{~h} 30 \mathrm{~min}$ post-cure step at $140{ }^{\circ} \mathrm{C}$ in a convection oven analyzed by: (A) TEM; (B) SEM; and (C) optical microscopy at $10 \times$ magnification.

Table 1. Heating rates of carbon nanotubes (CNTs) in tung oil. Values are presented in ${ }^{\circ} \mathrm{C} \mathrm{s}^{-1}$.

\begin{tabular}{cccc}
\hline \multirow{2}{*}{ Power (W) } & \multicolumn{3}{c}{ CNT Concentration } \\
\cline { 2 - 4 } & $\mathbf{0 . 0}$ wt \% & 0.1 wt \% & 0.25 wt \% \\
\hline 100 & $0.31 \pm(0.04)$ & $0.35 \pm(0.06)$ & $0.56 \pm(0.02)$ \\
200 & $0.65 \pm(0.19)$ & $0.80 \pm(0.02)$ & $1.17 \pm(0.06)$ \\
300 & $1.13 \pm(0.04)$ & $1.24 \pm(0.12)$ & $1.42 \pm(0.10)$ \\
400 & $1.53 \pm(0.05)$ & $1.66 \pm(0.06)$ & $1.89 \pm(0.06)$ \\
500 & $1.67 \pm(0.12)$ & $1.68 \pm(0.08)$ & $2.12 \pm(0.03)$ \\
\hline
\end{tabular}


When considering materials cured solely in a convection oven, no significant difference in the thermal behavior between resins with and without CNTs is observed, as can be seen in Figure 6. In Figure 6A, the DSC curves of samples with and without CNTs exhibit a very similar trace, with only discrete transitions, indicating that both materials are completely cured after being heated at $140{ }^{\circ} \mathrm{C}$ in a convection oven for $6 \mathrm{~h}$. Likewise, the TG curves of samples with and without CNTs (Figure 6B) are very similar up until $498^{\circ} \mathrm{C}$, when most of the materials have been completely degraded. One possible reason for the lower residue content of the resin cured in the presence of CNTs may be the catalytic action of metals present in the CNTs during the final stages of the thermal decomposition $\left(>470{ }^{\circ} \mathrm{C}\right)$, when high molecular weight and carbonized fragments experience further degradation in comparison to samples devoid of CNTs. Indeed, the CNTs have not been purified before being incorporated in the resin. They have a nominal ash content of $1.5 \mathrm{wt} \%$, rich in $\mathrm{Fe}$ and $\mathrm{Al}$. As will be discussed later in the text, before reaching temperatures $>470{ }^{\circ} \mathrm{C}$, the effects imparted by the use of CNTs are negligible in the thermal behavior of the system. Therefore it can be concluded that CNTs had little effect on the polymerization reaction carried out in a convection oven.
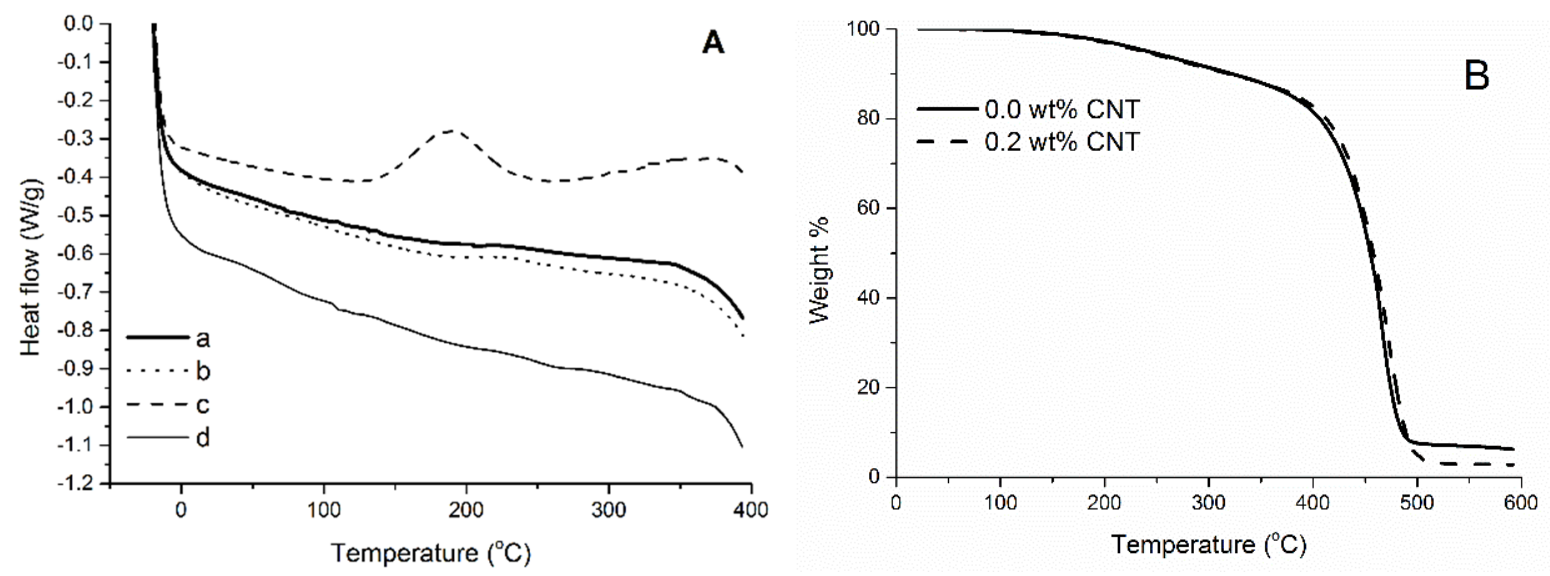

Figure 6. (A) DSC curves of: (a) unreinforced tung oil-based resin cured for $6 \mathrm{~h}$ at $140{ }^{\circ} \mathrm{C}$ in a convection oven, (b) tung oil-based resin reinforced with $0.2 \mathrm{wt} \%$ of CNTs and cured for $6 \mathrm{~h}$ at $140{ }^{\circ} \mathrm{C}$ in a convection oven, (c) a tung oil-based resin reinforced with $0.25 \mathrm{wt} \%$ CNTs microwaved at $100 \mathrm{~W}$ for $10 \mathrm{~min}$, followed by $200 \mathrm{~W}$ for $10 \mathrm{~min}$, and (d) a tung oil-based resin reinforced with $0.25 \mathrm{wt} \% \mathrm{CNTs}$ microwaved at $100 \mathrm{~W}$ for $10 \mathrm{~min}$, followed by $200 \mathrm{~W}$ for $10 \mathrm{~min}$, and a $2 \mathrm{~h} 10 \mathrm{~min}$ post-cure step at $140{ }^{\circ} \mathrm{C}$ in a convection oven; (B) TG curves of tung oil-based resins cured for $6 \mathrm{~h}$ at $140^{\circ} \mathrm{C}$ in a convection oven with and without CNTs.

The situation is completely different when the cure is carried out under microwaves. With the goal of finding the appropriate microwave conditions that result in a fully cured sample in the shortest possible time, it was hypothesized that due to the rapid and uniform heating obtained by microwave irradiation of well dispersed CNTs in the tung oil-based resin, the cure time can be drastically reduced in comparison to the regular cure carried out in a convection oven. After preliminary tests, an ideal microwave step was established with irradiation at $100 \mathrm{~W}$ for $10 \mathrm{~min}$, followed by irradiation at $200 \mathrm{~W}$ for $10 \mathrm{~min}$. When heating the crude monomer mixture under microwaves, a fine control over the microwave power utilized is necessary. If excessive heat is applied over a short time interval, the 
monomers boil before the polymerization is completed, resulting in an undesirable rigid foam structure. If excessive time is applied during the microwave cure, signs of thermal degradation are observed in the samples. The ideal microwave schedule obtained allowed for full consolidation of the thermoset, without formation of bubbles or cracks. Samples submitted to that schedule, however, still exhibit a residual cure peak when analyzed by DSC. In the DSC curve of a microwaved CNT/tung oil-based sample, the prominent exothermic peak at $190{ }^{\circ} \mathrm{C}$ reveals that the microwave cure step alone did not result in a completely cured material (Figure 6A). When testing alternative post-cure times, it has been found that after a post-cure step of $1 \mathrm{~h} 30 \mathrm{~min}$, the resin is still not completely cured (Figure S2). However, a completely cured sample is obtained when the material undergoes a $2 \mathrm{~h} 10 \mathrm{~min}$ post-cure at $140{ }^{\circ} \mathrm{C}$ in a convection oven after the microwave step (Figure 6A). The absence of exothermic peaks in Figure 6A (curve d) is indicative that the sample is fully cured. The post-cure of $2 \mathrm{~h} 10 \mathrm{~min}$ was arbitrarily selected so that the total reaction/cure time (microwave + convection oven) equals $2 \mathrm{~h} 30 \mathrm{~min}$.

These results show that a great decrease in heating time, from $6 \mathrm{~h}$, for the convection oven-only procedure, to $2 \mathrm{~h} 30 \mathrm{~min}$ total, for the microwave assisted step, is indeed successfully achieved. When one considers the final $2 \mathrm{~h} 10 \mathrm{~min}$ post-cure step as being common to both processes, the decrease in cure time is even more significant-3 h $50 \mathrm{~min}$ in the convection oven versus $20 \mathrm{~min}$ in the microwave. This significant decrease in cure time represents a great advantage for industrial applications where high throughput and shorter down times almost always translate into energy saving and process efficiency.

In Figure 7, a decrease of the exothermic peak at approximately $230{ }^{\circ} \mathrm{C}$ can be seen as the CNT loading is increased from $0.02 \mathrm{wt} \%$ to $0.25 \mathrm{wt} \%$. This phenomenon is consistent with the results in Table 1, where increasing concentrations of CNT result in higher heating rates. Indeed, when the same cure schedule is applied to tung oil-based composites of different CNT loadings, higher temperatures are achieved, during the microwave stage of the curing process, for the samples with higher CNT loadings. The higher temperatures ensure a faster polymerization rate for the system, and according to the DSC curves presented in Figure 7, it is possible to obtain a fully cured sample, with the optimized cure schedule, by introducing $0.25 \mathrm{wt} \%$ of CNTs. It is important to note that a higher temperature is observed for the exothermic peak of post-cured samples (Figure 7A-C) in comparison to a non-post-cured sample (Figure 6A). This occurs because, for partially cured samples, post-curing in the convection oven enables an increase of the crosslink density. Therefore, post-cured samples require higher temperatures to resume the polymerization, which translates into an exothermic peak at a higher temperature during the DSC analysis.

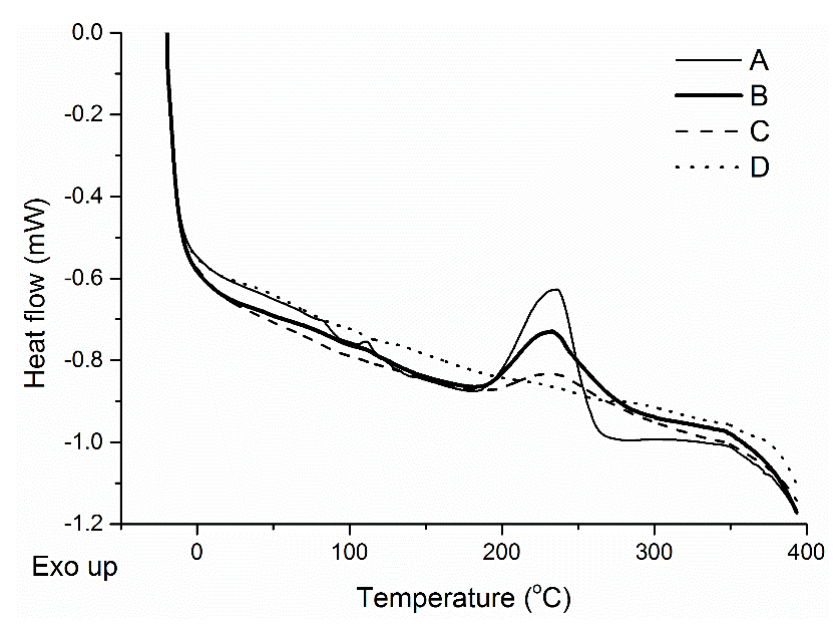


Figure 7. DSC curves of CNT/tung oil-based composites with various CNT loading, microwaved at $100 \mathrm{~W}$ for $10 \mathrm{~min}$, followed by $200 \mathrm{~W}$ for $10 \mathrm{~min}$, and a $2 \mathrm{~h} 10 \mathrm{~min}$ post-cure step at $140{ }^{\circ} \mathrm{C}$ in a convection oven. The CNT loading in the composites is (A) $0.02 \mathrm{wt} \%$; (B) $0.10 \mathrm{wt} \%$; (C) $0.20 \mathrm{wt} \%$; and (D) $0.25 \mathrm{wt} \%$.

\subsection{Dynamic Mechanical Analysis and Thermogravimetry}

From a theoretical standpoint, there is no difference in the number of polymerization sites between samples, since the cure reaction proceeds mostly by cationic initiation, and for all experiments the same amount of BFE was used. Nevertheless, it is known that increasing temperatures increase the transfer reaction during the cationic polymerization, which may result in lower molecular weights. When samples containing evenly dispersed CNTs are microwaved, localized heat is instantly generated at each CNT particle and immediately dissipated to the surrounding medium. Overall, a quicker and more homogeneous heating of the system is obtained in comparison to conventional heating, or microwaving in the absence of CNTs. In seeking shorter cure times by combining CNTs and microwaves, it has been observed that an increase in CNT loading results in faster heating rates. As a consequence, more monomer molecules are simultaneously heated, which leads to faster polymerization rates and overall lower mechanical properties (Figure 8). Furthermore, partial polymer degradation can also increase with increasing CNT loading, leading to poorer mechanical properties and higher soluble content, as will be discussed later in the text.

In Table 2, a clear trend is observed for the decrease in storage modulus $\left(E^{\prime}\right)$ at $25{ }^{\circ} \mathrm{C}$ as the $\mathrm{CNT}$ loading is increased from 0.00 to $0.20 \mathrm{wt} \%$ (entries $1-4$, Table 2). When the CNT loading is increased from 0.20 to $0.25 \mathrm{wt} \%$ (entries 4 and 5, Table 2), a slight increase in $E$ ' is observed. Indeed, an increase of only $0.05 \mathrm{wt} \%$ in CNTs is not sufficient to make an appreciable difference between the samples. The numbers are in fact very similar, with a difference of only $2.5 \mathrm{MPa}$. Consistent trends are observed when considering $E^{\prime}$ at $T_{\mathrm{g}}+50^{\circ} \mathrm{C}$.

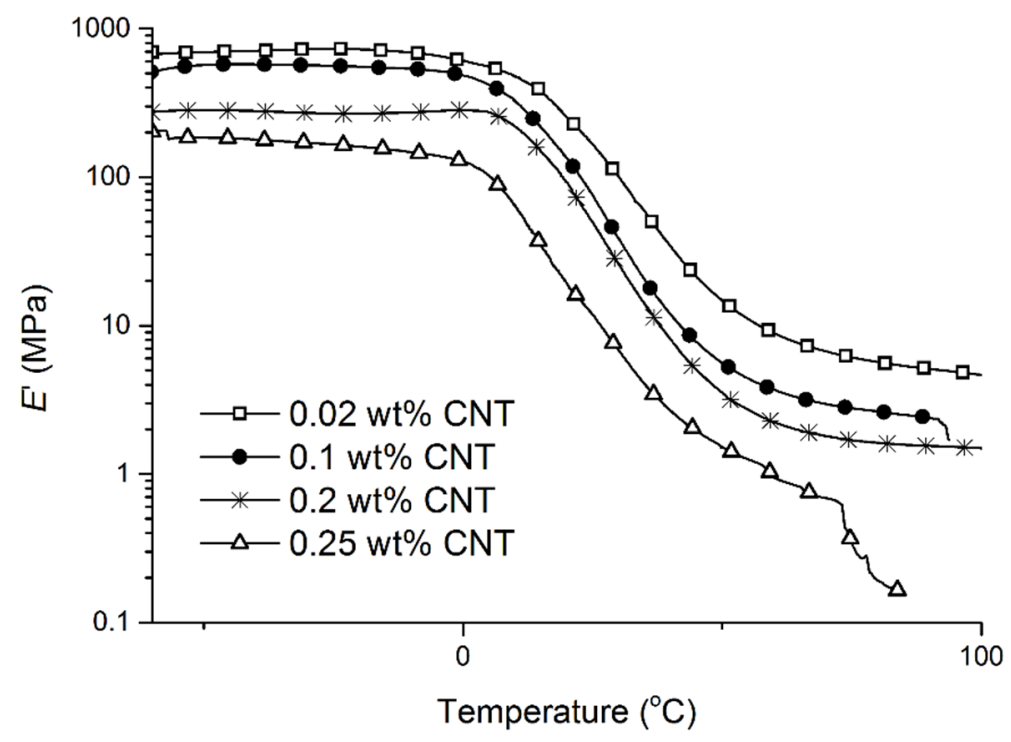

Figure 8. Storage modulus vs. temperature curves of a tung oil-based resin reinforced with different amounts of CNTs and cured under microwaves at $100 \mathrm{~W}$ for $10 \mathrm{~min}$, followed by $200 \mathrm{~W}$ for $10 \mathrm{~min}$, and a $2 \mathrm{~h} 10 \mathrm{~min}$ post-cure step at $140{ }^{\circ} \mathrm{C}$ in a convection oven. 
Table 2. Glass transition temperature $\left(T_{\mathrm{g}}\right)$ and Storage modulus $\left(E^{\prime}\right)$ at $25{ }^{\circ} \mathrm{C}$ as determined by dynamic mechanical analysis (DMA), and thermogravimetric analysis (TGA) results for samples cured either in a convection oven, or under microwaves.

\begin{tabular}{|c|c|c|c|c|c|c|c|c|}
\hline Entry & Cure Process & $\begin{array}{c}\text { Post-Cure } \\
\left(140^{\circ} \mathrm{C}\right)\end{array}$ & $\begin{array}{c}\text { CNT Loading } \\
\text { (wt \%) }\end{array}$ & $T_{\mathrm{g}}\left({ }^{\circ} \mathrm{C}\right)$ & $\begin{array}{c}E^{\prime} \text { at } 25^{\circ} \mathrm{C} \\
\text { (MPa) }\end{array}$ & $\begin{array}{c}E^{\prime} \text { at } T_{\mathrm{g}}+50^{\circ} \mathrm{C} \\
\text { (MPa) }\end{array}$ & $T_{90}{ }^{\mathrm{d}}\left({ }^{\circ} \mathrm{C}\right)$ & $T_{50}{ }^{\mathrm{e}}\left({ }^{\circ} \mathrm{C}\right)$ \\
\hline 1 & Microwave $^{\text {a }}$ & $2 \mathrm{~h} 10 \mathrm{~min}$ & 0.00 & 32.2 & 104.1 & 3.8 & 324 & 455 \\
\hline 2 & Microwave $^{a}$ & $2 \mathrm{~h} 10 \mathrm{~min}$ & 0.02 & 33.6 & 99.6 & 3.3 & 269 & 419 \\
\hline 3 & Microwave $^{a}$ & $2 \mathrm{~h} 10 \mathrm{~min}$ & 0.10 & 34.4 & 81.4 & 2.8 & 327 & 449 \\
\hline 4 & Microwave $^{\text {a }}$ & $2 \mathrm{~h} 10 \mathrm{~min}$ & 0.20 & 33.2 & 48.9 & 1.5 & 369 & 449 \\
\hline 5 & Microwave $^{a}$ & $2 \mathrm{~h} 10 \mathrm{~min}$ & 0.25 & 31.2 & 51.4 & 2.0 & 374 & 456 \\
\hline 6 & Oven $^{b}$ & $2 \mathrm{~h} 10 \mathrm{~min}$ & 0.00 & 28.3 & 154.0 & $-c$ & 320 & 455 \\
\hline 7 & Oven ${ }^{b}$ & $2 \mathrm{~h} 10 \mathrm{~min}$ & 0.25 & 38.1 & 200.8 & 5.1 & 317 & 458 \\
\hline
\end{tabular}

${ }^{\text {a }}$ Sample submitted to $10 \mathrm{~min}$ irradiation at $100 \mathrm{~W}$, followed by 10 min irradiation at $200 \mathrm{~W}$; ${ }^{\mathrm{b}}$ Sample heated at $140{ }^{\circ} \mathrm{C}$ for $3 \mathrm{~h} 50 \mathrm{~min}$ in a convection oven; ${ }^{\mathrm{c}}$ The sample broke consistently before $T_{\mathrm{g}}+50{ }^{\circ} \mathrm{C}$ was attained; ${ }^{\mathrm{d}}$ Temperature at which $10 \mathrm{wt} \%$ of the sample has degraded; ${ }^{\mathrm{e}}$ Temperature at which $50 \mathrm{wt} \%$ of the sample has degraded.

When the sample is cured exclusively in a convection oven, in the absence of CNTs (entry 6, Table 2), a storage modulus at $25^{\circ} \mathrm{C}$ of $154 \mathrm{MPa}$ is obtained. It is expected that the unique resin composition used in this work results in samples that exhibit mechanical properties different than similar systems, prepared by the cationic polymerization of vegetable oils and other comonomers. When one takes into consideration the relative concentrations of tung oil and divinylbenzene (DVB) in the resin composition, the observed values for storage modulus $\left(E^{\prime}\right)$ at $25{ }^{\circ} \mathrm{C}$ reported here are in line with previously published data from similar systems. For example, it has been reported that cationic resins containing $54 \mathrm{wt} \%$ of tung oil and $35 \mathrm{wt} \%$ of DVB exhibit $E^{\prime}$ at $25^{\circ} \mathrm{C}$ of approximately $1050 \mathrm{MPa}$ [38]. When the relative amount of oil in the resin is increased to $70 \mathrm{wt} \%$, while the amount of DVB is decreased to $15 \mathrm{wt} \%$, a natural decrease in the mechanical properties is expected. Hence, the observed value of $154 \mathrm{MPa}$ for $E^{\prime}$ at $25^{\circ} \mathrm{C}$ for the unreinforced resin cured in the convection oven (Table 2, entry 6) is considered in line with previous studies. Likewise, it has been reported that cationic samples containing $45 \mathrm{wt} \%$ of olive or canola oils and $15 \mathrm{wt} \%$ of DVB exhibit room temperature $E$ ' values of $220 \mathrm{MPa}$ and $450 \mathrm{MPa}$, respectively [40]. These values show the variability in mechanical properties with changes in the resin composition. Therefore, when the specific composition of the resin studied in this work is taken into account, the mechanical properties reported for the unreinforced resin cured in the convection oven can be considered in line with similar studied systems.

$E^{\prime}$ at $25^{\circ} \mathrm{C}$ for the unreinforced resin cured in the convection oven is significantly higher than that obtained by a similar sample, cured in the microwave (entry 1, Table 2), corroborating the idea that the rapid cure experienced by the samples cured in the microwave compromises the mechanical properties. Additionally, during the DMA experiments, the sample consistently broke prematurely, before $T_{\mathrm{g}}+50{ }^{\circ} \mathrm{C}$ was attained (Table 2 , entry 6 ). Unlike samples cured in the microwave, when a tung oil-based resin reinforced with CNTs is cured in a convection oven, a significant increase in $E^{\prime}$ at $25{ }^{\circ} \mathrm{C}$ is observed (entries 6 and 7, Table 2), showing the reinforcement character of CNTs. A comparison of the $E^{\prime}$ values at $25^{\circ} \mathrm{C}$ and at $T_{\mathrm{g}}+50{ }^{\circ} \mathrm{C}$ for composites reinforced with $0.25 \mathrm{wt} \%$ of CNTs cured in the microwave and in a convection oven (entries 5 and 7, Table 2) shows very clearly the detrimental effect of the expedite microwave cure to the mechanical properties of the material. 
Despite the observed changes in storage modulus of samples cured in the microwave with different CNT loadings, the values measured for the $T_{\mathrm{g}}$ of these samples are fairly consistent, varying only between $31.2{ }^{\circ} \mathrm{C}$ and $34.4{ }^{\circ} \mathrm{C}$, with no regular pattern (entries 1-5, Table 2). For samples cured exclusively in a convection oven, however, addition of CNTs results in a significant increase of the $T_{\mathrm{g}}$ (entries 6 and 7, Table 2). It is possible that covalent bonding occurs between defect sites on the CNTs and the resin components through possible free radical reactions during the conventional cure of the materials due to the extended heating at elevated temperatures, altering the dynamics of the regular matrix-reinforcement interactions for the system. Along the same lines, it is speculated that the slight difference in $T_{\mathrm{g}}$ between the unreinforced resin cured in the oven and in the microwave lies in the cure mechanism being different in the two processes. A much deeper investigation of the cure mechanisms, which is beyond the intended scope of the current manuscript, is necessary in order to fully understand this phenomenon. Better suited, single-component systems might allow for a clearer analysis of the problem. It is important to highlight, however, that the difference in $T_{\mathrm{g}}$ is only $3.9{ }^{\circ} \mathrm{C}$ (Table 2 , entries 1 and 6).

Thermogravimetric analysis was used to assess differences in thermal stability between samples cured in a convection oven and under microwaves with varying amounts of CNTs (Table 2, Figure 9). The temperatures at which $90 \mathrm{wt} \%\left(T_{90}\right)$ and $50 \mathrm{wt} \%\left(T_{50}\right)$ of the samples remain during the thermal degradation are presented in Table 2. It can be observed that, for CNT composites cured under microwaves, increasing CNT loadings result in an increase in $T_{90}$ (entries $2-5$, Table 2), suggesting that the addition of CNTs result in materials that start degrading at a higher temperature when compared to their CNT-free counterparts. When $T_{50}$ is considered, a very similar trend is observed, with the only exception being the samples containing $0.1 \mathrm{wt} \%$ CNTs and $0.2 \mathrm{wt} \%$ CNTs (entries 3 and 4, Table 2), for which no appreciable difference was detected. When a sample devoid of CNTs is cured under microwaves, its resulting thermal stability is very similar to that of a sample cured in a convection oven, with $T_{90}$ varying only by $4{ }^{\circ} \mathrm{C}$, and $T_{50}$ being exactly the same (entries 1 and 6 , Table 2 ). The difference in the resulting thermal stability of samples cured under microwaves with and without CNTs, indicates that a different polymerization process occurs depending on the presence of CNTs. As discussed earlier, the localized heat generated by the absorption of microwaves by CNTs prompts the simultaneous growth of multiple polymer chains, which results in a matrix with lower molecular weight, and lower thermal stability. The addition of CNTs to the resin, for samples cured exclusively in a convection oven, does not impart a significant change in $T_{90}$ and $T_{50}$, with changes of only $3{ }^{\circ} \mathrm{C}$ in both cases (entries 6 and 7 , Table 2). This expected behavior confirms that CNTs have no effect in the heating process taking place in the convection oven, acting more as a reinforcement than as a heating agent. Due to the small CNT loading used, no significant difference was observed in the thermal stability of the two samples cured exclusively in a convection oven (entries 6 and 7, Table 2). 


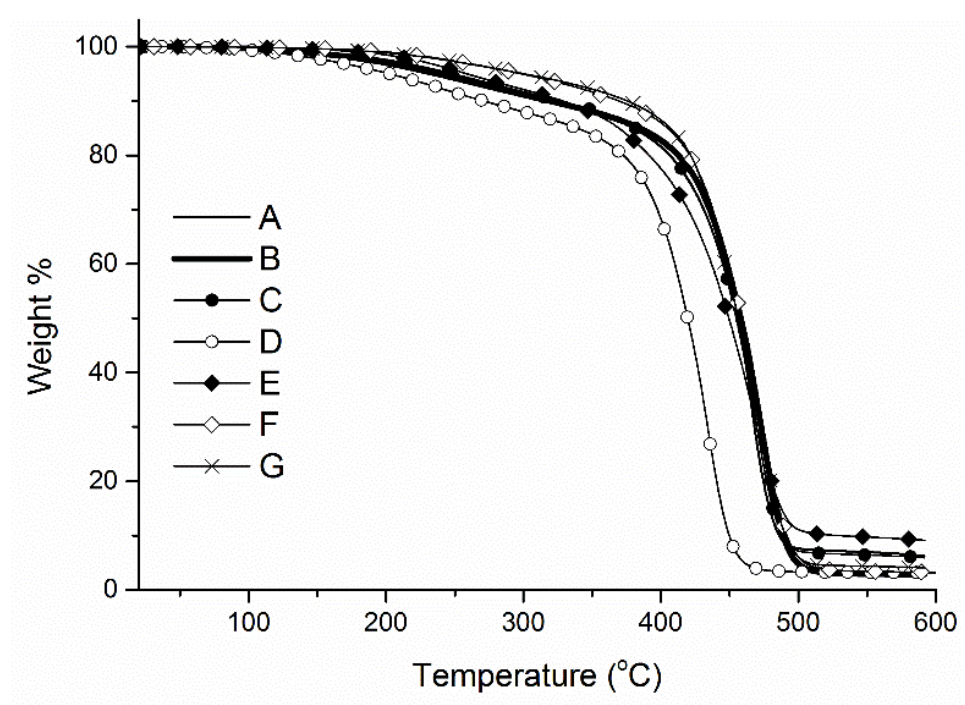

Figure 9. Thermogravimetric analysis (TGA) curves of tung oil-based resins, cured in a convection oven for $6 \mathrm{~h}$ at $140{ }^{\circ} \mathrm{C}$, reinforced with (A) $0.00 \mathrm{wt} \% \mathrm{CNTs}$; and (B) $0.25 \mathrm{wt} \%$ CNTs, and tung oil-based resins, cured under microwaves at $100 \mathrm{~W}$ for $10 \mathrm{~min}$, followed by $200 \mathrm{~W}$ for $10 \mathrm{~min}$, and a $2 \mathrm{~h} 10 \mathrm{~min}$ post-cure step at $140^{\circ} \mathrm{C}$, in a convection oven, reinforced with (C) 0.00 wt \% CNTs; (D) 0.02 wt \% CNTs; (E) 0.10 wt \% CNTs; (F) 0.20 wt \% CNTs; and $(\mathrm{G}) 0.25 \mathrm{wt} \% \mathrm{CNTs}$.

\subsection{Soxhlet Extraction}

After Soxhlet extraction with methylene chloride, the samples cured exclusively in a convection oven exhibited, on average, $17 \mathrm{wt} \%$ of soluble material, while samples cured under microwaves exhibit, on average, $19 \mathrm{wt} \%$ of soluble material. These numbers are in agreement with previously published data on similar tung oil-based resins [38]. The percentage of soluble material extracted is inversely proportional to the crosslink density of the polymer, therefore, it can be concluded that samples cured under microwaves are only slightly less cross-linked than those cured exclusively in a convection oven.

The soluble material recovered after Soxhlet extraction from each sample was analyzed by ${ }^{1} \mathrm{H}$ NMR spectroscopy (Figure 10) and the results reveal that the extracts correspond to partially reacted tung oil and/or tung oil oligomers. Figure 10C shows a standard ${ }^{1} \mathrm{H}$ NMR spectrum of a conjugated triglyceride with peaks at 4.00-4.40 ppm, corresponding to the glycerol methylenes, and the series of multiplets at $5.20-6.50 \mathrm{ppm}$, corresponding to the protons of conjugated $\mathrm{sp}^{2}$ hybridized carbons. In Figure 10A,B, the spectra match very closely that of tung oil, with the exception of peaks $>5.5 \mathrm{ppm}$, denoting that at least some of the carbon-carbon double bonds in tung oil have reacted, most likely forming soluble oligomers. 


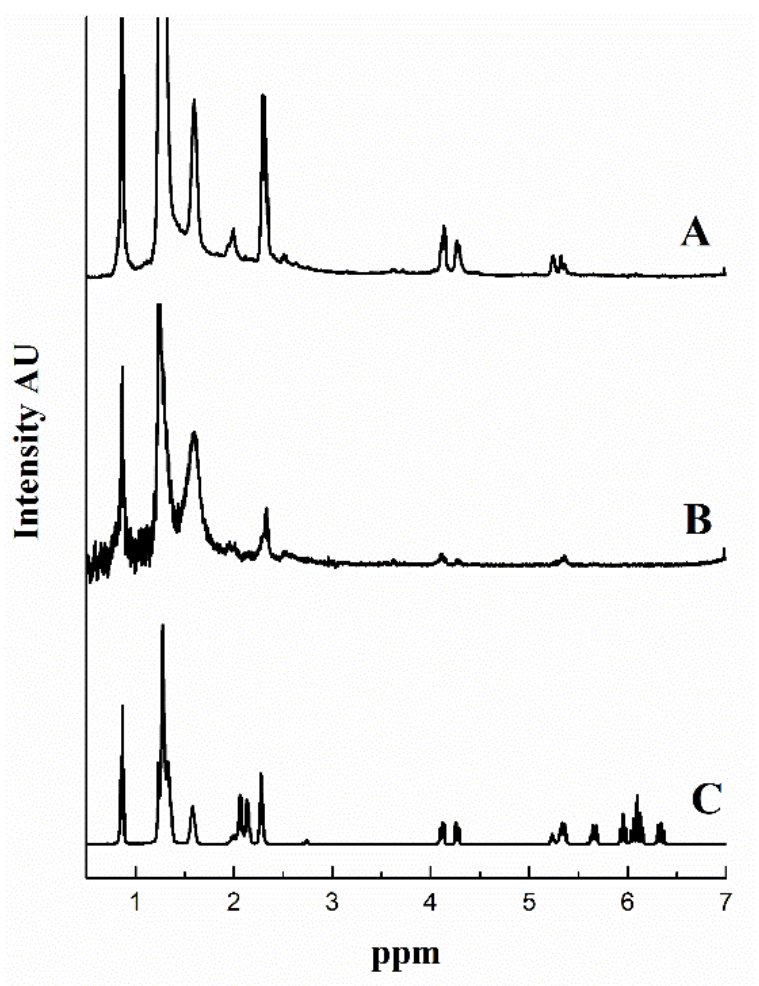

Figure 10. ${ }^{1} \mathrm{H}$ NMR spectra of (A) tung oil-based resin cured for $6 \mathrm{~h}$ at $140{ }^{\circ} \mathrm{C}$ in a convection oven without CNTs, (B) tung oil-based resin reinforced with $0.25 \mathrm{wt} \% \mathrm{CNTs}$ microwaved at $100 \mathrm{~W}$ for $10 \mathrm{~min}$, followed by $200 \mathrm{~W}$ for $10 \mathrm{~min}$, and a $2 \mathrm{~h} 10 \mathrm{~min}$ post-cure step at $140{ }^{\circ} \mathrm{C}$ in a convection oven, and (C) tung oil.

\section{Conclusions}

After preliminary tests, an ideal resin composition was established with 70 wt \% of tung oil, 15 wt $\%$ of DVB, 10 wt $\%$ of ST, 3 wt $\%$ of soybean oil, and 2 wt $\%$ of BF 3 . OEt 2 . DEA and DSC experiments show that the complete polymerization of the resin is attained after heating the sample at $140{ }^{\circ} \mathrm{C}$ in a convection oven for $6 \mathrm{~h}$. No significant differences have been detected between resins cured exclusively in a convection oven with or without CNTs. When CNT composites are cured under microwaves, a strong dependence of the cure with the CNT loading is observed. In order to drastically reduce cure times, an ideal microwave cure schedule was established with irradiation at $100 \mathrm{~W}$ for $10 \mathrm{~min}$, followed by irradiation at $200 \mathrm{~W}$ for $10 \mathrm{~min}$, and a post-cure step of $2 \mathrm{~h} 10 \mathrm{~min}$ at $140{ }^{\circ} \mathrm{C}$ in a convection oven. It is possible to obtain a fully cured material under microwaves by introducing $0.25 \mathrm{wt} \%$ of CNTs into the resin. With the data presented, it was shown that the microwave cure conditions need to be adjusted based on the desired CNT loading, or that the CNT loading needs to be adjusted in order to achieve a desired reaction time. This represents an advantage, since it allows one to easily tailor processing conditions to meet pre-specified needs. The expedited microwave cure, however, compromises the mechanical properties of the materials. Samples cured under microwaves are only slightly less cross-linked than those cured exclusively in a convection oven, and ${ }^{1} \mathrm{H}$ NMR spectroscopy analysis of composite extracts reveals that at least some of the carbon-carbon double bonds in tung oil have reacted, most likely forming soluble oligomers. 


\section{Acknowledgments}

The authors thank the College of Science and Mathematics and the Chemistry Department at Georgia Southern University for the financial support.

\section{Author Contributions}

Rafael L. Quirino conceived and designed the experiments; Brenda Beckler prepared all polymers and composites; Steven Morris performed the NMR experiments; Kyle Edwards determined the heating rates of CNTs; Amanda Payne contributed with imaging experiments and analysis; Brenda Beckler and Madeline Smith performed all mechanical testing and analyzed the corresponding data; Rafael L. Quirino contributed reagents/materials/analysis tools; Rafael L. Quirino and Madeline Smith wrote the paper.

\section{Conflicts of Interest}

The authors declare no conflict of interest.

\section{References}

1. Hernández, N.; Williams, R.C.; Cochran, E.W. The battle for the "green" polymer. Different approaches for biopolymer synthesis: Bioadvantaged vs. bioreplacement. Org. Biomol. Chem. 2014, 12, 2834-2849.

2. Mülhaupt, R. Green polymer chemistry and bio-based plastics: Dreams and reality. Macromol. Chem. Phys. 2013, 214, 159-174.

3. Quirino, R.L.; Larock, R.C. Sugarcane bagasse composites from vegetable oils. J. Appl. Polym. Sci. 2012, 126, 860-869.

4. Pfister, D.P.; Larock, R.C. Cationically cured natural oil-based green composites: Effect of the natural oil and the agricultural fiber. J. Appl. Polym. Sci. 2012, 123, 1392-1400.

5. Quirino, R.L.; Larock, R.C. Synthesis and properties of soy hull-reinforced biocomposites from conjugated soybean oil. J. Appl. Polym. Sci. 2009, 112, 2033-2043.

6. Andjelkovic, D.D.; Min, B.; Ahn, D.; Larock, R.C. Elucidation of structural isomers from the homogeneous rhodium-catalyzed isomerization of vegetable oils. J. Agric. Food Chem. 2006, 54, 9535-9543.

7. Quirino, R.L.; Larock, R.C. Rh-based biphasic isomerization of carbon-carbon double bonds in natural oils. J. Am. Oil Chem. Soc. 2012, 89, 1113-1124.

8. Philippaerts, A.; Goossens, S.; Vermandel, W.; Tromp, M.; Turner, S.; Geboers, J.; Tendeloo, G.V.; Jacobs, P.A.; Sels, B.F. Design of Ru-zeolites for hydrogen-free production of conjugated linoleic acids. Chem. Sus. Chem. 2011, 4, 757-767.

9. Saebo, A.; Skarie, C.; Jerome, D.; Haroldsson, G. Conjugated linoleic acid compositions and methods of making same. U.S. Patent 6,410,761, 25 June 2002.

10. Jain, V.P.; Proctor, A.; Lall, R. Pilot-scale production of conjugated linoleic acid-rich soy oil by photoirradiation. J. Food Sci. 2008, 73, E183-E192.

11. Li, F.; Larock, R.C. Synthesis, structure and properties of new tung oil-styrene-divinylbenzene copolymers prepared by thermal polymerization. Biomacromolecules 2003, 4, 1018-1025. 
12. Liu, C.; Yang, X.; Cui, J.; Zhou, Y.; Hu, L.; Zhang, M.; Liu, H. Tung oil based monomer for thermosetting polymers: Synthesis, characterization, and copolymerization with styrene. Bioresources 2012, 7, 447-463.

13. Espinosa, L.M.; Meier, M. Plant oils: The perfect renewable resource for polymer science?! Eur. Polym. J. 2010, 47, 837-852.

14. Pfister, D.P.; Baker, J.R.; Henna, P.H.; Lu, Y.S.; Larock, R.C. Preparation and properties of tung oil-based composites using spent germ as a natural filler. J. Appl. Polym. Sci. 2008, 108, 3618-3625.

15. Meiorin, C.; Aranguren, M.I.; Mosiewicki, M.A. Vegetable oil/styrene thermoset copolymers with shape memory behavior and damping capacity. Polym. Int. 2012, 61, 735-742.

16. Sibaja, B.; Sargent, J.; Auad, M.L. Renewable thermoset copolymers from tung oil and natural terpenes. J. Appl. Polym. Sci. 2014, 131, 41155-41162.

17. Humar, M.; Lesar, B. Efficacy of linseed- and tung-oil-treated wood against wood-decay fungi and water uptake. Int. Biodeterior. Biodegrad. 2013, 85, 223-227.

18. Wang, Q.; Padua, G.W. Properties of zein films coated with drying oils. J. Agric. Food Chem. 2005, 53, 3444-3448.

19. Das, K.; Ray, D.; Banerjee, C.; Bandyopadhyay, N.R.; Mohanty, A.K.; Misra, M. Novel materials from unsaturated polyester resin/styrene/tung oil blends with high impact strengths and enhanced mechanical properties. J. Appl. Polym. Sci. 2011, 119, 2174-2182.

20. Wutticharoenwong, K.; Soucek, M.D. synthesis of tung-oil-based reactive diluents. Macromolar. Mater. Eng. 2010, 295, 1097-1106.

21. Huang, K.; Liu, Z.; Zhang, J.; Li, S.; Li, M.; Xia, J.; Zhou, Y. Epoxy monomers derived from tung oil fatty acids and its regulable thermosets cured in two synergistic ways. Biomacromolecules 2014, $15,837-843$.

22. Wang, Y.; Padua, G.W. Structure characterization of films from drying oils cured under infrared light. J. Appl. Polym. Sci. 2010, 115, 2565-2572.

23. Dias, A.N.; Kurz, M.H.S.; Fagundes, C.A.M.; Caldas, S.S.; Clementin, R.M.; D’Oca, M.G.M.; Primel, E.G. Evaluation of ASTM D6584 method for biodiesel ethyl esters from sunflower oil and soybean/tallow mixture and for biodiesel methyl esters from tung oil and soybean/tung mixture. J. Braz. Chem. Soc. 2014, 25, 1161-1165.

24. Arjmand, M.; Apperley, T.; Okoniewski, M.; Sundararaj, U. Comparative study of electromagnetic interference shielding properties of injection molded versus compression molded multi-walled carbon nanotube/polystyrene composites. Carbon 2012, 50, 5126-5134.

25. Gorrasi, G.; D’Ambrosio, S.; Patimo, G.; Pantani, R. Hybrid clay-carbon nanotube/PET composites: Preparation, processing, and analysis of physical properties. J. Appl. Polym. Sci. 2014, 131, 40441-40448.

26. Paul, A.; Grady, B.P.; Ford, W.T. PMMA composites of single-walled carbon nanotubes-graft-PMMA. J. Appl. Polym. Sci. 2014, 131, 39884-39895.

27. Yang, S.; Yu, S.; Cho, M. Influence of thrower-stone-wales defects on the interfacial properties of carbon nanotube/polypropylene composites by a molecular dynamics approach. Carbon 2013, 55, 133-143. 
28. Laredo, E.; Bello, A.; Diaz, J.; Grimau, M.; Martinez-Tong, D.; Wu, D.; Wu, L. Effect of cold-crystallization on the AC and DC conductive properties of polylactide biocomposites with carboxylic or neat large aspect ratio MWCNT. Polym. Comp. 2013, 34, 67-76.

29. Zhang, H.; Chen, Z. Fabrication and characterization of electrospun PLGA/MWNTs/ hydroxyapatite biocomposite scaffolds for bone tissue engineering. J. Bioact. Compat. Polym. 2010, 25, 241-259.

30. Lu, Y.; Larock, R.C. Fabrication, morphology and properties of soybean oil-based composites reinforced with continuous glass fibers. Macromol. Mater. Eng. 2007, 292, 1085-1094.

31. Sathishkumar, M.; Nagarajan, S.; Velan, P.S.; Dinesh, M.; Ponnuswamy, A. Microwave-assisted clean synthesis of amides via aza-wittig reaction under solvent-free condition. J. Braz. Chem. Soc. 2011, 22, 2065-2069.

32. Cesarino, V.; Cesarino, I.; Moraes, F.C.; Machado, S.A.S.; Mascaro, L.H. Carbon nanotubes modified with $\mathrm{SnO}_{2}$ rods for levofloxacin detection. J. Braz. Chem. Soc. 2014, 25, 502-508.

33. Vazquez, E.; Prato, M. carbon nanotubes and microwaves: interactions, responses, and applications. ACS Nano 2009, 3, 3819-3824.

34. Lin, Y.; Baggett, D.W.; Kim, J.W.; Siochi, E.J.; Connell, J.W. Instantaneous formation of metal and metal oxide nanoparticles on carbon nanotubes and graphene via solvent-free microwave heating. ACS Appl. Mat. Interfaces 2011, 3, 1652-1664.

35. Vennerberg, D.; Quirino, R.L.; Kessler, M.R. A novel microwave-assisted carbothermic route for the production of copper-carbon nanotube metal matrix composites directly from copper oxide. Adv. Eng. Mat. 2013, 15, 366-372.

36. Chang, J.; Liang, G.; Gu, A.; Cai, S.; Yuan, L. The production of carbon nanotube/epoxy composites with a very high dielectric constant and low dielectric loss by microwave curing. Carbon 2012, 50, 689-698.

37. Rangri, V.K.; Bhuyan, M.S.; Jeelani, S. Comparative study of microwave and thermal curing of high temperature epoxy/Carbon nanotubes polymer nanocomposites and their properties. Int. J. Nanosci. 2011, 10, 1225-1230.

38. Li, F.; Larock, R.C. Thermosetting polymers from cationic copolymerization of tung oil: Synthesis and characterization. J. Appl. Polym. Sci. 2000, 78, 1044-1056.

39. Quirino, R.L. Commercial CLA and its Chemical Use. In RSC Catalysis Series; Sels, B., Philippaerts, A., Eds.; Royal Society of Chemistry: Cambridge, UK, 2014; Volume 19, pp. 117-130.

40. Andjelkovic, D.D.; Valverde, M.; Henna, P.; Li, F.; Larock, R.C. Novel thermosets prepared by cationic copolymerization of various vegetable oils-Synthesis and their structure-property relationships. Polymer 2005, 46, 9674-9685.

(C) 2015 by the authors; licensee MDPI, Basel, Switzerland. This article is an open access article distributed under the terms and conditions of the Creative Commons Attribution license (http://creativecommons.org/licenses/by/4.0/). 